\title{
PENERAPAN TEKNIK FERMENTASI DAN PENGERINGAN UNTUK MENINGKATKAN KUALITAS BIJI KAKAO GUNA MENINGKATKAN PENDAPATAN MASYARAKAT DI DESA GUNUNG SERAWAN KECAMATAN BANDAR MASILAM KABUPATEN SIMALUNGUN
}

\author{
Emmy Harso Kardhinata ${ }^{1)}$, Hot Setiado ${ }^{2)}$ \\ ${ }^{1)}$ Fakultas Pertanian, Program Studi Agroteknologi, Universitas Sumatera Utara \\ Email: harso@usu.ac.id \\ ${ }^{2)}$ Fakultas Pertanian, Program Studi Agroteknologi, Universitas Sumatera Utara \\ Email: setiado@yahoo.com
}

\begin{abstract}
ABSTRAK
Desa Gunung Serawan, Kecamatan Bandar Masilam terletak sekitar $145 \mathrm{~km}$ dari kota Medan. Sebagian masyarakat yang memiliki ladang dan lahan pekarangan telah memanfaatkan dengan menanami kakao. Kualitas biji kakao yang dihasilkan masih rendah sehingga nilai jualnya juga rendah. Akibatnya pendapatan petani dari kebun kakao juga masih rendah. Rendahnya kualitas biji kakao antara lain bersumber dari proses fermentasi yang kurang sempurna serta proses pengeringan yang kurang baik. Proses fermentasi masih menggunakan karungkarung bekas sehingga banyak biji yang busuk. Pengeringan biji kakao dilakukan di halaman rumah dan masih mengandalkan panas dari sumber matahari sehingga permasalahan muncul pada kondisi cuaca kurang baik. Proses pengeringan seperti ini menyebabkan biji kakao masih mengandung kadar air yang tinggi sehingga dapat menyebabkan busuk terserang cendawan atau jamur. Kelompok tani Sri Gunung dan Serawan Jaya telah mencoba mengatasi hambatan-hambatan ini. Faktor kurangnya modal dan pengetahuuan menyebabkan program kelompok tani tersebut mengalami kendala. Tim pengabdian pada masyarakat USU memberikan solusi dengan cara pembuatan peralatan fermentasi dan pengeringan biji kakao yang dirakit bersama-sama dengan masyarakat agar selain mereka akan memiiki peraatan yang mereka butuhkan juga terjadi transfer ilmu dan teknologi yang dapat mereka kembangkan kelak ke depan.
\end{abstract}

Kata Kunci: Fermentasi, Pengeringan

\section{PENDAHULUAN}

Desa Gunung Serawan, Kecamatan Bandar Masilam, Kabupaten Simalungun terletak di bagian tengah Sumatera Utara. Jarak dari Medan (ibukota provinsi sekitar $145 \mathrm{~km}$ yang dapat ditempuh dengan kendaraan bermotor (mobil dan sepeda motor) dengan waktu lebih kurang 2,5 jam. Desa Gunung Serawan berada di sekitar perkebunan kelapa sawit baik milik pemerintah maupun swasta. Sebagian besar masyarakat hidup sebagai petani tanaman pangan dan palawija, peternak, petani perkebunan dan sebagai buruh di perkebunan yang ada di sekitarnya. Sebahagian petani perkebunan memiliki kebun kelapa sawit namun tidak begitu luas, dan hasil yang rendah sehingga tidak dapat memenuhi kebutuhan hidup. Oleh karena itu sebagian masyarakat petani kelapa sawit sudah berusaha mengkonversi lahan sawit menjadi kakao sebagaimana yang pernah mereka lakukan pada era 1990-an. 
Emmy. et.al. Penerapan Teknik Fermentasi Dan Pengeringan Untuk Meningkatkan Kualitas Biji Kakao Guna Meningkatkan Pendapatan Masyarakat Di Desa Gunung Serawan Kecamatan Bandar Masilam Kabupaten Simalungun

Gabungan Kelompok Tani (Gapoktan) Sri Gunung, Serawan Jaya merupakan kelompok yang sudah beralih menanam komoditi kakao. Alasan mereka menanam kakao karena dapat memanfaatkan lahan pekarangan. Meski sebagian tanaman milik masyarakat masih merupakan sisa tanaman lama yang menggunakan bibit sembarang, namun sudah dimuai dengan menanam tanaman kakao baru yang menggunakan benih bersertifikat. Teknik perawatan dan kultur teknis sudah didapatkan dari para penyuluh pertanian dan perkebunan maupun melalui pengabdian masyarakat perguruan tinggi. Kendala yang kini dihadapi masyarakat adalah harga jual biji kakao yang masih relatif rendah sehingga menyebabkan pendapatan petani kakao belum memenuhi harapan masyarakat.

\subsection{Permasalahan Mitra}

Tanaman kakao dari gapoktan Sri Gunung dan kelompok tani Serawan Jaya telah menghasilkan biji kakao menggunakan bibit yang sebagian berasal dari tanaman lama dan sebagian dari tanaman yang baru menghasilkan. Proses pasca panen yang dilakukan masing sangat sederhana sehingga menghasilkan biji kakao dengan kualitas kurang baik. Salah satu faktor mengapa rendahnya kualitas biji kakao adalah berkaitan dengan penanganan pasca panen. Proses fermentasi biji kakao masih menggunakan karungkarung plastik yang tidak layak digunakan sehingga prosesnya tidak berjalan dengan baik. Hasil fermentasi yang kurang sempurna ini menyebabkan biji kakao banyak yang rusak akibat busuk dan pecah.

Pengeringan juga meruapakan proses yang sangat penting untuk menghasilkan biji kakao yang berkuaitas. Kondisi masyarakat yang pendapatannya masih kurang menyebabkab proses pengeringan hanya mengandalkan sumber panas matahari. Kendala dijumpai ketika cuaca mendung dalam waktu yang lama sehingga menyebabkan biji kakao tidak kering sempurna. Kadar air yang masih tinggi pada biji kakao dapat menyebabkan busuk dan terserang jamur.

Berdasarkan beberapa permasalahan di atas, tahun ini dengan bantuan Lembaga Pengabdian Masyarakat USU mencoba memberikan sumbangsih berupa teknologi fermentasi menggunakan bak-bak kayu untuk meningkatkan terjadinya proses fermentasi yang lebih baik. Untuk menghadapi cuaca yang tidak menentu, diberikan peralatan penjemuran yang terbuat dari baja ringan dan plastik UV untuk menjamin proses pengeringan lebih baik.

Pemberian bantuan paket teknologi ini dibarengi dengan penyuluhan dan diskusi serta pembuatan alat fermentasi dan alat pengeringan secara bersama-sama. Dengan demikian masyarakat tidak hanya mengerti secara teori tetapi juga secara praktek Metode ini diharapkan ke depan masyarakat mampu mengembangkan sendiri peralatan yang mereka butuhkan.

\section{TARGET LUARAN}

Untuk menghasilkan biji kakao yang berkualitas tinggi tidak cukup hanya dengan menggunakan bibit yang bersertifikat serta kultur teknis yang sesuai dengan standar, namun juga harus memlaui proses pasca panen yang tepat. Salah satu tahap pasca panen adalah proses fermentasi biji kakao. Tujuan dari proses fermentasi adalah untuk mematikan lembaga biji agar tidak tumbuh sehingga perubahan-perubahan di dalam biji kakao akan mudah terjadi, seperti warna keping biji, peningkatan aroma dan rasa, perbaikan konsistensi keping biji, dan untuk melepaskan pulp.

Tahap lainnya adalah proses pengeringan biji kakao. Pengeringan bertujuan untuk menurunkan kadar air biji dari $60 \%$ sampai pada kondisi kadar air dalam biji tidak dapat menurunkan kualitas biji dan biji tidak ditumbuhi cendawan. Pengeringan biji kakao dapat dilaksanakan dengan sinar matahari 
Emmy. et.al. Penerapan Teknik Fermentasi Dan Pengeringan Untuk Meningkatkan Kualitas Biji Kakao Guna Meningkatkan Pendapatan Masyarakat Di Desa Gunung Serawan Kecamatan Bandar Masilam Kabupaten Simalungun

atau pengeringan buatan. Dengan sinar matahari dibutuhkan waktu 2 - 3 hari, tergantung kondisi cuaca, sampai kadar air biji menjadi 7-8\%. Dengan pengeringan buatan, pengeringan biji kakao berlangsung pada temperatur $65-68^{\circ} \mathrm{C}$.

Apa yang telah dilakukan oleh kelompok tani Sri Gunung dan Serawan Jaya adalah pelaksanaan proses fermentasi yang kurang sempurna sehingga banyak biji yang rusak. Selain itu proses pengeringan dilaksanakan hanya dengan menggunakan sinar matahari dan dijemur di pelataran atau halaman rumah. Kondisi ini menyebabkan biji dengan bendabenda lain seperti batu, puntung rokok, kayu, dan lain-lain sehingga menurunkan kualitas biji kakao.

Langkah-langkah yang akan dilakukan adaah membuat alat fermentasi biji kakao dengan menggunakan bahan dari papankayu agar proses fermentasi berjalan lebih baik. Selain itu membuat alat pengering yang terbuat dari baja ringan dengan penutup dari plastik uv agar proses pengeringan dapat berlangsung setiaap saat tanpa terganggu oleh cuaca.

\section{METODE PELAKSANAAN}

Pelaksanaan pengabdian pada masyarakat dilakukan dengan metode ceramah, diskusi dan praktek langsung di lapangan. Tahapan pelaksanaan kegiatan tersbut adalah sebagai berikut :

\subsection{Pembuatan Alat Fermentasi Biji Kakao}

Langkah pertama yang dilakukan adalah penyiapan bahanbahan yang dibutuhkan untuk pembuatan kotak fermentasi. Bahanbahan dan alat-alat yang diperlukan berupa papan, broti, dan triplek, termomoeter, meteran, gergaji, palu, martil, pahat, paku, dan lainlain. Bahan dan alat seluruhnya disediakan oleh Lembaga Pengabdian pada Masyarakat (LPPM) Universitas Sumatera Utara . Alat-alat sebagian disediakan oleh kelompok tani. Kotak fermentasi berukuran panjang $\mathrm{x}$ lebar $\mathrm{x}$ tinggi $80 \times 80 \times 100 \mathrm{~cm}$ dan diharapkan dapat dibuat sebanyak 10 unit

\subsection{Pembuatan Alat pengering biji kakao}

Bahan yang dibutuhkan untuk pembuatan alat pengering terdiri dairi baja ringan, ring baja ringan skrup, plastik UV dan jaring plastik. Semua bahan yang digunakan berasal dari sumbangan Lembaga Pengabdian pada Masyarakat (PPM) USU. Pembuatan alat penjemuran atau pengeringan ini dilaksanakan bersama-sama dengan masyarakat. Ukuran alat penjemur/pengering ini panjang x lebar x tinggi $150 \times 100 \times 200$ $\mathrm{cm}$ dan diharapkan dapat terbentuk 10 unit.

\subsection{Penyuluhan}

Penyuluhan dilaksanakan berkaitan dengan proses pascapanen kakao pada umumnya dan khusus tentang proses fermentasi dan proses pengeringan biji kakao. Penyuluhan dilaksanakan sebelum dan setelah pembuatan alat fermentasi dan pengeringan dibantu dengan demonstrasi penggunaan alat-alat.

\section{HASIL LUARAN YANG DICAPAI}

Kegiatan pengabdian pada masyarakat dilaksanakan melalui beberapa tahap yaitu persiapan, sosialisasi, demonstrasi dan evaluasi.

\subsection{Persiapan}

Tahapan persiapan dilakukan di Medan dan di lokasi pengabdian yaitu di Desa Gunung Serawan Kecamatan Bandar Masilam. Kegiatan persiapan meliputi perancangan model alat pengeringan dan aat fermentasi yang akan dibuat. Model alat pengeringan dan kotak fermentasi didisain terlebih dahulu dan dilakukan perhitungan bahan yang akan digunakan. Dilakukan kunjungan ke lokasi pengabdian untuk berdiskusi dengan masyarakat kelompok tani untuk menentukan lokasi pembuatan serta bentuk dan ukuran alat pengering dan kotak fermentasi yang akan dibuat. 
Emmy. et.al. Penerapan Teknik Fermentasi Dan Pengeringan Untuk Meningkatkan Kualitas Biji Kakao Guna Meningkatkan Pendapatan Masyarakat Di Desa Gunung Serawan Kecamatan Bandar Masilam Kabupaten Simalungun

\subsection{Sosialisasi}

Sosialisasi selain dihadiri oeh anggota kelompok tani juga dihadiri Kepala Desa Gunung Serawan, Penyuluh Pertanian juga tokoh yang berperan penting dalam pembangunan pertanian dan perkebunan di desa tersebut.

\subsection{Pembuatan Alat Pengering/Penjemur Kakao}

Pelaksanaan program ini dilakukan dengan cara mengundang ahli di bidang pertukangan dan meibatkan anggota kelompok tani.

Pembuatan alat penjemur dilakukan di 5 lokasi yang terpisah, yaitu di rumah warga yang ditunjukk berdasarkan musyawarah mufakat oleh kelompok tani. Setiap lokasi penempatan penjemuran kakao diharapkan dapat menampung hasil biji kakao setiap anggota kelompok tani yang berada di daerah sekitarnya. Teknik pengaturan penjemuran dilakukan sepenuhnya berdasarkan kesepakatan anggota kelompok tani.

Penggunaan alat penjemur pengering kakao ini diharapkan dapat mengatasi permasalahan yang ada selama ini yaitu proses pengeringan yang tidak sempurna akibat faktor cuaca. Alat pengering/penjemur biji kakao ini terbuat dari baja ringan yang sangat kuat tahan terhadap proses perkaratan sehingga diharapkan dapat bertahan lama. Alat penjemur ini berbeda jauh dengan alat yang digunakan sebeumnya yang terbuat dari bahan kayu yang mudah lapuk dan tidak tahan lama.

Atap atau penutup yang digunakan pada saat sebeumnya terbuat dari plastik putih yang mudah sobek dan tidak bekerja secara maksimal. Pada alat penjemur yang baru dibuat dari bahan pastik UV. Plastik UV ialah plastik khusus yang dapat menyaring sinar ultraviolet dengan kadar tertentu. Pada umumnya Plastik UV yang dijual dipasaran tertulis angka $6 \%, 12 \%$, dan 14\%. Angka tersebut adalah kandungan UV protector yang dimiliki plastik UV tersebut. UV protector ditambahkan mempergunakan lapisan bahan kimia pada plastik. Semakin tinggi kandungan UV protektor biasanya plastik UV akan berwarna putih susu makin gelap. Plastik UV yang digunakan pada kegiatan ini adalah 12\%. Keuntungan Plastik Ultra Violet pada GreenHouse dibanding memakai yang lainnya adalah

a. Relatif lebih murah daripada bahan lainnya. Selain bisa melindungi dari radiasi matahari, Plastik UV juga bisa melindungi tanaman dari hujan, mencegah air masuk ke dalam alat penjemur

b. Mampu melindungi dari hama atau hewan lainnya.

c. Meminimalisir penggunaan pestisida dan bahan kimia lainnya.
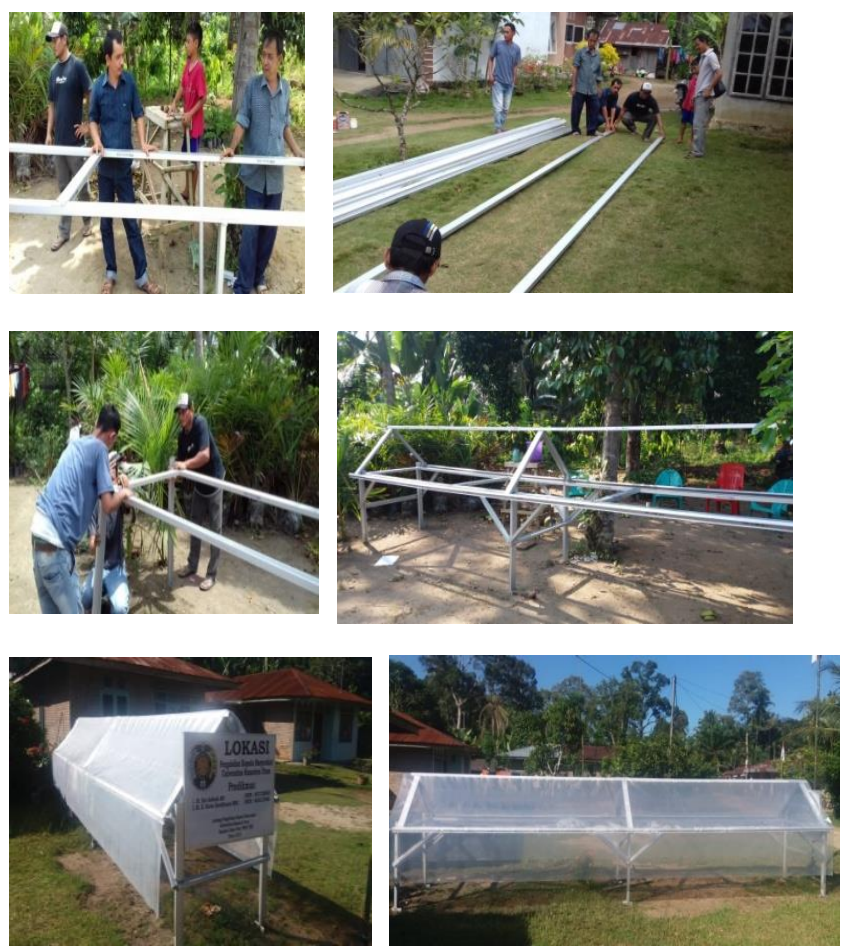

Gambar 1: Pemotongan dan pembentukan kerangka alat penjemur/pengering 
Emmy. et.al. Penerapan Teknik Fermentasi Dan Pengeringan Untuk Meningkatkan Kualitas Biji Kakao Guna Meningkatkan Pendapatan Masyarakat Di Desa Gunung Serawan Kecamatan Bandar Masilam Kabupaten Simalungun

Pelaksanaan pembuatan alat penjemuran/pengeringan biji kakao sudah diselesaikan $100 \%$. Target mula-mula akan dibangun sebanyak 10 unit dengan ukuran panjang 3x2 (tigaxdua) meter. Ukuran baja ringan yang terdapat di lokasi berukuran panjang 6 meter. Untuk menghemat biaya pemotongan maka berdasarkan musyawarah dengan kelompok tani diubah menjadi ukuran panjang 6x2 meter sesuai dengan ukuran baja ringan yang tersedia. Dengan demikian jumlah alat penjemuran/pengeringan yang dibangun menjadi 5 unit.

\subsection{Kotak Fermentasi biji kakao}

Petani seringkali tidak melakukan proses fermentasi biji kakao karena kurang pengetahuan mengenai teknologi fermentasi biji kakao. Faktor lainnya karena harga kakao yang tidak berbeda antara fermentasi dan tidak fermentasi. Proses fermentasi yang dilakukan pda biji kakao dapat meningkatkan kualitas kelas mutu kakao (Adnan dan Pandu 2010).

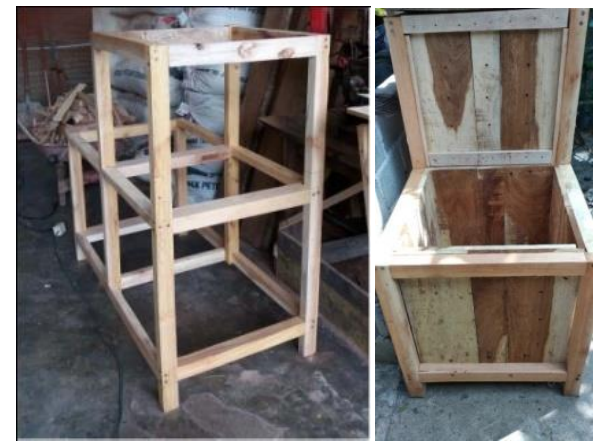

Gambar 2: Kerangka kotak fermentasi kakao yang terbuat dari kayu

Keterangan : Menyimpan Kakao sambil difermentasi, Dimensi : PxLxT 100 x 40 x $80 \mathrm{~cm}$, Bahan : Kayu papan, Kaso, Kapasitas : $30-50 \mathrm{~kg}$

Proses fermentasi di dalam kotak ini memerlukan waktu 6 hari. Dalam proses fermentasi terjadi penurunan berat sampai 25\%. Cara Fermentasi Kakao dengan kotak/peti fermentasi yaitu dengan cara memasukkan biji kakao ke dalam kotak setelah itu kotak ditutup dengan karung goni/daun pisang. Pada hari ke 3 (setelah 48 jam) dilakukan pembalikan agar fermentasi biji merata. Pada hari ke 6 biji-biji kakao dikeluarkan dari kotak fermentasi dan siap untuk dijemur.

Kotak fermentasi yang teah selesai dikerjakan sebanyak 10 unit. Terbuat dari papan dan kayu, kotak fermentasi ini akan dapat digunakan paling sedikit 10 tahun. Dengan jumlah 10 unit yang tersebar di beberapa anggota kelompok tani diharapkan untuk sementara dapat menampung biji kakao yang dihasilkan petani di desa ini.

\subsection{Konsolidasi dengan Petani}

Kotak fermentasi akan dibagi seseuai dengan kelompok alat penjemuran/pengeringan. Untuk setiap alat penjemuran/pengeringan dilengkapi dengan unit kotak fermentasi. Jumlah 10 unit sudah tentu belum mencukupi dibanding dengan jumlah anggota keompok tani. Untuk itu Tim Pengabdian Masyarakat USU mensosialisasikan penggunaan, pembagian kelompok berdasarkan lokasi dan dilanjutkan dengan penyerahan alat penjemuran/pengeringan kakao.

\section{KESIMPULAN DAN SARAN}

Pelaksanaan pengabdian pada masyarakat berjalan dengan baik dan lancar. Kelompok tani dan masyarakat dapat bekerjasama dengan baik dan menyambut gembira program ini. Beberapa alasan yang disampaikan antara lain, pertama keinginan masyarakat untuk mengembaikan kejayaan desa tersebut sebagai penghasi biji kakao di masa lampau. Kedua keinginan masyarakat untuk meningkatkan kualitas biji kakao yang dihasilkan untuk dapat lebih baik dari yang diperoleh pada masa lalu akibat proses penjemuran/pengeringan dan fermentasi yang kurang baik sehingga harga di pasar sangat rendah. 
Emmy. et.al. Penerapan Teknik Fermentasi Dan Pengeringan Untuk Meningkatkan Kualitas Biji Kakao Guna Meningkatkan Pendapatan Masyarakat Di Desa Gunung Serawan Kecamatan Bandar Masilam Kabupaten Simalungun

\section{UCAPAN TERIMA KASIH}

Kegiatan pengabdian masyarakat yang telah dilaksanakan telah dapat diselesaikan dengan dan didapat hasil yang diharapkan dapat diadopsi oleh masyarakat. Dalam pelaksanaan kegiatan ini, tim peneliti banyak mendapat bantuan dari bebagai kalangan, sehingga kegiatan pengabdian ini dapat terlaksana. Sehubungan dengan hal tersebut, tim peneliti mengucapkan terima kasih kepada LPPM USU yang telah membiayai kegiatan ini.

\section{DAFTAR PUSTAKA}

Adnan dan Pandu Laksono. 2010. Pengkajian Model Fermentasi Yang Tepat Pada Biji Kakao Di Kabupaten Jayapura, Papua. Prosiding Seminar Nasional BPTP Papua, Ha. 141-147.

Badan Litbang Pertanian. 2007. Prospek dan Arah Pengembangan Agribisnis Kakao. Ed II. 26 hal.

Bakri, A.H., FX Soegabyo dan P. Sembiring, 1989. Kelapa sebagai naungan kakao di PT. P.P. Londom Sumatera Indonesia. Kump. Makalah Seminar Sehari Tumpangsari Kelapa-Kakao. Pusat Penelitian Bandar Kuala, Sumatera Utara, 18 Januari 1989. 25p

[BPS] Badan Pusat Statistik. 2016. Data statistik kependudukan Desa Gunung Serawan. Kecamatan Bandar Huluan dalam angka.

Direktorat Jendral Perkebunan. 2008. Gerakan Peningkatan Produksi dan Mutu Kakao Nasional. Bahan presentasi Dirjenbun pada bulan Nopember 2008 di hadapan Tim Itjen Deptan. 26 hal.

Google maps. 2014. Peta interpretasi wilayah Gunung Serawan beserta tutupannya. (diakses pada 2 Fabruari 2017).

Elna Karmawati, dkk. 2010. Budidaya dan Pasca Panen Kakao. Pusat Penelitian dan Pengembangan Perkebunan.

Firdausil AB, Nasriati, A. Yani. 2008. Teknologi Budidaya Kakao. Balai Besar Pengkajian dan Pengembangan Teknologi Budidaya dan Pasca Panen KAKAO 93 Pertanian, Badan Penelitian Dan Pengembangan Pertanian. 26p.

Hatta Sunanto. 1994. Cokelat, Pengolahan Hasil dan Aspek Ekonominya. Kanisius.

Mulato Sri, Sukrisno Widyotomo, Misnawi, dan Edy Suharyanto, 2005. Pengolahan Produk Primer dan Sekunder Kakao. Pusat Penelitian Kopi dan Kakao Indonesia, Jember

Rijadi Subiantoro. 2009. Teknik Pembibitan Tanaman Kakao. Politeknik Negeri Lampung.

Rubyo, R., Siswanto, S. 2010. Peningkatan Produksi dan Pengembangan Kakao (Theobroma cacao L). di Indonesia. Jurnal Tanaman Industri dan Penyegar Vol 3, No 1 (2012).

Siagian, I.P.S., Balonggu, S., Jonatan, G. 2014. Pertumbuhan Bibit Kakao (Theobroma cacao L.) dengan Pemberian Pupuk NPK dan Hayati. Jurnal Online Agrokoteknologi . ISSN No. 2337-6597, Vol.2, No.2 : 447459, Maret 2014.

Wahyudi T, T.R. Panggabean, dan Pujiyanto, 2008. Panduan Lengkap Kakao. Penebar Swadaya.Jakarta 